\title{
Lateral visual hemifield asymmetry and sex differences in recognizing low and high spatial frequency filtered faces
}

\author{
Lina María Perilla-Rodríguez, Rui de Moraes Junior, and Sérgio Sheiji Fukusima \\ Universidade de São Paulo, Ribeirão Preto, SP, Brazil
}

\begin{abstract}
The present study investigated whether low and high spatial frequency filtered images of faces were recognized differently when briefly presented in the right and the left visual fields of men and women. The method of confidence rating was applied to assess pooled Receiver Operating Characteristic curves based on z scores and the d' parameter of Signal Detection Theory for recognition indices, in addition to response times. The results showed that men better recognized low spatial frequency filtered faces than high spatial frequency filtered faces in both visual fields, suggesting that both the right and left hemispheres in males prioritize low spatial frequencies to recognize faces. The results for women were similar to men only when the faces were shown in the left visual field. When the faces were presented in the right visual field, women better recognized high spatial frequency filtered faces, suggesting that the left hemisphere in females prioritizes high spatial frequencies, whereas the right hemisphere in females prioritizes low spatial frequencies to recognize faces. Keywords: facial recognition, spatial frequencies, brain asymmetry, sex differences, Signal Detection Theory - confidence rating.
\end{abstract}

Received 22 December 2012; received in revised form 23 October 2013; accepted 29 October 2013. Available online 23 December 2013.

\section{Introduction}

Functional brain asymmetry refers to how information is processed more or less efficiently by each brain hemisphere in different tasks (Springer, \& Deutsch, 1993). Specifically for face recognition, one of the factors that appears to contribute to this asymmetry is the spatial frequency (SF) components of face images. Pre-processing performed by retinal SF channels tuned to different bands of the spectrum (Campbell, \& Robson, 1968) supports high-level cognitive operations in the cortex, such as analytical and holistic processing (de Heering, Turati, Rossion, Bulf, Goffaux, \& Simion, 2008). Analytical processing refers to the processing of a single feature independently of the context (i.e., eyes, nose, and mouth on a face; Schwarzer, \& Zauner, 2003), unlike holistic processing that refers to integrating the features into a gestalt (i.e., in a face, this type of processing interconnects the facial features; Goffaux, \& Rossion, 2006; Maurer, Le Grand, \& Mondloch, 2002). The availability of the spatial frequency components of a visual image may vary depending on the exposure duration. High spatial frequencies (HSF)

Lina María Perilla-Rodríguez, Rui de Moraes Junior, and Sérgio Sheiji Fukusima, Departmento de Psicologia, Universidade de São Paulo, Ribeirão Preto, Brazil. Correspondence regarding this article should be directed to: Lina María Perilla-Rodríguez, FFCLRP - Universidade de São Paulo, Programa de Pós-Graduação em Psicobiologia, Av. Bandeirantes, 3900, Monte Alegre, Ribeirão Preto, SP, CEP 14040-901, Brasil. Phone: +55-16-3602-4448. Fax: +55-163633-2660. E-mail: linamariapr@hotmail.com. are extracted subsequently to low spatial frequencies (LSF; Goffaux, \& Rossion, 2006; Sergent, 1982b). HSF mediate analytical processing, and LSF mediate holistic processing (Boeschoten, Kemner, Kenemans, \& Van Engelan, 2005; Hills, \& Lewis, 2009).

According to findings on left hemisphere (LH) and right hemisphere $(\mathrm{RH})$ specialization in analytical and holistic processing (Springer, \& Deutsch, 1993), Sergent (1982b) proposed the SF hemispheric specialization hypothesis. This hypothesis states that SF information is differentially processed in each hemisphere. The $\mathrm{LH}$ is better equipped to process later-available components of HSF stimuli, and the RH is enhanced to process earlier-available components of LSF information. This hypothesis has been supported by studies that used different types of stimuli. Simple visual stimuli, such as gratings, were exposed in divided visual field behavioral tasks that measure psychophysical parameters (Kitterle, Christman, \& Conesa, 1993) and response time (RT; Proverbio, Zani, \& Avella, 1997). Additionally, SF components were assessed using hierarchical letterforms, which included a letter (global component) made of smaller letters (local components), that contained high and low luminance transitions, respectively. Han, Weaver, Murray, Kang, Yund, \& Woods (2002) presented hierarchical letterforms centered and lateralized in a functional magnetic resonance imaging (fMRI) study. Evidence to support SF asymmetry hypothesis also came from behavioral and fMRI studies that Fourier-transformed and filtered complex visual stimuli, such as natural scenes (Coubard et al., 2011; Peyrin, Baciu, Segebarth, \& Marendaz, 
2004; Peyrin, Chauvin, Chokron, \& Marendaz, 2003) and faces (Keenan, Whitman, \& Pepe, 1989; Whitman, \& Keegan, 1991).

Interest in the human face as an object of study has been increasing since the end of the last century. In addition to its social and evolutionary relevance, behavioral and neuroimaging data indicate that face processing depends more on SF content than on other stimuli (Collin, Liu, Troje, McMullen, \& Chaudhuri, 2004; Yue, Tjan, \& Biederman, 2006). Thus, it became a model for SF perception in complex visual stimuli. Nevertheless, few studies have investigated the relationship between SF brain asymmetry in face recognition.

Keenan et al. (1989) performed a face recognition task with SF masking in a divided visual field. The results corroborated Sergent's hypothesis (1982b), although they presented the faces tachistoscopically only for $10 \mathrm{~ms}$. Researchers have found differential processing between previously learned faces and new faces with face presentation onsets of 200-400 ms (Münte, Brack, Grootheer, Wieringa, Matzke, \& Johannes, 1998), 300-600 ms (Paller et al., 2003; Paller, Gonsalves, Grabowecky, Bozic, \& Yamada, 2000), 400-600 ms (Yovel, Levy, Grabowecky, \& Paller, 2003), 110-600 ms (Barbeau, Taylor, Regis, Marquis, Chauvel, \& LiégeoisChauvel, 2008), and > 200 ms (Münte, Urbach, Düzel, $\&$ Kutas, 2000).

Whitman, \& Keegan (1991) conducted a study in which pairs of faces were tachistoscopically presented at LSF or HSF in the right visual field (RVF) or left visual field (LVF), and the participant provided samedifferent responses. The results partially supported the SF hypothesis of hemispheric specialization. Presentations in the LH/RVF produced more errors, and this difference was greater for faces in the LSF. In the RH/LVF, faces presented in a LSF had lower response times and lower error rates. Although an exposure time of $200 \mathrm{~ms}$ was used, two stimuli were presented simultaneously, possibly impairing face encoding. Additionally, the eccentricity of the face's inner edge was $<1.3$ degrees of visual angle. This distance enabled the stimuli presented to be focused on the binocular convergence area, which may invalidate the technique of divided visual field. Finally, only men (n =26) participated in the study.

A sample composed of men shows that researchers do not usually select participants based on sex or are restricted to male participants to avoid gender effects. The literature rarely addresses sex differences in SF hemispheric asymmetry, which may be important, given that sex can modulate patterns of hemispheric dominance (Voyer, 1996). The study by Keenan et al. (1989) discussed above investigated the influence of sex in their sample of 15 men and 15 women, but no differences were found. Peyrin, Chokron, Guyader, Gout, Moret, \& Marendaz (2006a) also used the divided visual field with the presentation of SF filtered complex stimuli, but they used scenes instead of faces. The results showed an effect of SF asymmetry only in the male sample (12 of 24 participants).
To elucidate this issue, the present study investigated sex differences in hemispheric asymmetry using a face recognition task under the influence of spatial filtering and assessed accuracy and RTs. We used a modified divided visual field method based on the technique used by Tripathy, Levi, Ogmen, \& Harden (1995), which sought to quantify any perceived length distortion for vertical bars presented across the blind spot so that we could use a higher exposure time compared with the traditional method and ensure that the face was processed. Moreover, unlike other studies, this experiment was conducted in two phases: memorization and recognition (despite the matching task design, which is widely used in the literature). The short duration of each matching-task trial may impair the transfer of SF band information to short-term visual memory (Gao, \& Bentin, 2011). The results presented herein are interpreted in terms of perceptual processes of face processing and coding because the decrease in visual short-term memory retention is not influenced by the SF spectrum (Gao, \& Bentin, 2011). Finally, we mixed YesNo and confidence rating methods of Signal Detection Theory (SDT; Macmillan, \& Creelman, 2005) to calculate the participant's performance.

\section{Methods}

\section{Participants}

Forty volunteers (mean age, 27.7 years; standard deviation [SD], 7.57 years; range, 19-52 years), including 20 male students (mean age, 27.4 years; SD, 5.62 years; range, $22-44$ years) and 20 female students (mean age, 28.0 years; SD, 9.26 years; range, 19-52) from the University of São Paulo, participated in this study after providing informed consent according to the current rules in Brazil on human experiments (process no. 268/2006 - 2006.1.1368.59.9). All of the participants had normal or corrected visual acuity in both eyes. All of them were right handed, based on a 16-item questionnaire adapted from the Edinburgh Inventory (Oldfield, 1971). The mean handedness score on the Edinburgh Inventory was 85 (SD, 10.10) for men and 84 (SD, 9.18) for women.

\section{Stimuli}

Stimuli were presented against a black background at a viewing distance of $40 \mathrm{~cm}$, subtended by 12.68 $\times 10.62$ degrees of visual angle. Fifty-six gray-scale pictures of Caucasian faces in the frontal view with a neutral expression (half female) were selected from the Mendes, Arrais, \& Fukusima (2009) face database. The faces were Fourier-transformed and multiplied by low-pass and high-pass Gaussian filters that preserved either LSF $(<6$ cycles per face [cpf] or .56 cycles per degree [cpd]) or HSF ( $>24 \mathrm{cpf}$ or $2.26 \mathrm{cpd}$ ). MATLAB 7.4 (MathWorks) was used for image processing. After filtering, the images were inverse-Fourier-transformed. External features (hair, ear, and neck) of LSF filtered faces, HSF filtered faces, and unfiltered images were hidden by surrounding the face with an oval window 
and fitting this image onto a black rectangle $(213 \times$ 255 pixels) using Photoshop 7.0 (Adobe). The faces presented for the recognition test were also duplicated on the screen with eccentricity of 3.58 degrees of visual angle (inner edge; Figure 1).
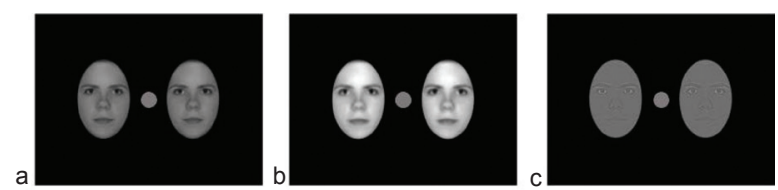

Figure 1. Example of (a) unfiltered, (b) low spatial frequency filtered, and (c) high spatial frequency filtered faces.

\section{Procedure}

The participants were comfortably seated on a chair in a dark room in front of a computer while resting their head on a chinrest. The experiment was completed in two phases: memorization and recognition. The order of stimulus presentation in each phase was randomized by Superlab 2.0 (Cedrus).

In the memorization phase, the participants were required to keep in memory 14 pictures (half female) of unfiltered faces. Each face was shown without a time restriction at the center of the computer screen. Four sessions were required to complete this task. In the last session, the subjects were asked to recognize the 14 faces by responding "yes" or "no" to indicate whether the face presented on the monitor had been previously presented. When any misidentification occurred, the participants were reexposed to the faces until total recognition was achieved. The subjects were not given any explicit instructions about learning strategies. This phase was performed on a computer that was different from the one used for the second phase, although it was in the same room.

The recognition phase was performed immediately after the memorization phase. The latter included 84 trials, with 14 memorized faces (half female) in each filtering condition (14 LSF filtered, 14 HSF filtered, and 14 unfiltered), for a total of 42 target faces and 42 distractor stimuli in the same conditions without any stimulus repetition. The participants were first instructed to centrally place a red cross that was presented until they pressed the spacebar on the keyboard. After showing a face for $300 \mathrm{~ms}$, a blank screen was presented for $500 \mathrm{~ms}$. The participants were then asked to indicate as accurately and quickly as possible whether the face was new (a distractor) or had been presented in the memorization phase (a target). The confidence in their response was rated by pressing one of six keys on a numeric keypad according to a 6-category scale, from category 1 ("I am certain that I do not recognize it") to category 6 ("I am certain that I recognize it"). The other categories represented intermediate confidence levels for the response. Before the experimental session, the participants completed five practice trials to ensure they understood the task.

In the second phase, the stimuli were presented to the participant using dichoptic images (Figure 2) proposed by Tripathy et al. (1995). A mirror $(30 \mathrm{~cm}$ height $\times 35$ $\mathrm{cm}$ length $\times .3 \mathrm{~cm}$ width) was placed vertically and perpendicularly to the midline of the monitor using a support attached to the monitor. Through this support, an adjustable black cardboard occluder was placed to prevent direct sight on the left and right half of the monitor by the left and right eye, respectively, but it allowed the observer to perceive the image reflected in the mirror through a gap between the occluder and mirror. The back of the mirror was covered with black paper. Even with the occurrence of saccades, this adaptation in the divided visual field prevented the stimulus presented in one visual hemifield from reaching the ipsilateral nasal retina, given the presence of the occluder. In the hemifield that was not occluded, the information could only reach the nasal retina because of the eccentricity adopted. The stimulus viewed through the gap was mirrored (i.e., inverted) so that the binocular effect could occur, and the participants perceived only one face in the hemifield that was not occluded. The sample was independent for each hemisphere tested, with 20 participants (half female) for the right and 20 participants for the left.

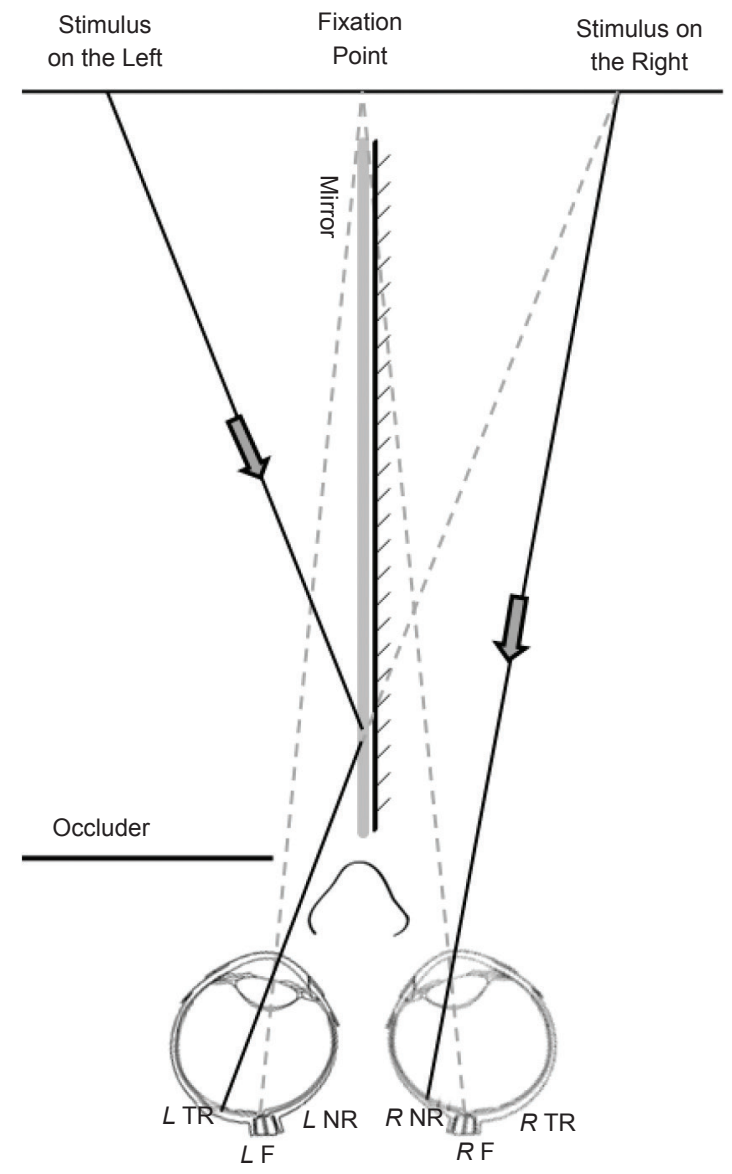

Figure 2. Dichoptic presentation of the image through the mirror and occluder. The face presented on the left half was reflected on the mirror and had its image projected on the temporal retina of the left eye. The right eye viewed the right half of the screen directly, and the image presented in this half was projected on the nasal retina. Thus, all of the information was initially processed in the left hemisphere. This process was inverted to test the right hemisphere. F, fovea; NR, nasal retina; TR, temporal retina; $\mathrm{L}$, left; $\mathrm{R}$, right. Figure based on the model image of Tripathy et al. (1995). 


\section{Data and statistical analysis}

Confidence ratings and mean response times were recorded. Recognition performance was calculated using SDT (Macmillan, \& Creelman, 2005). Receiver Operating Characteristic (ROC) curves were calculated using the $\mathrm{z}$ scores of the cumulative frequency of responses to the categories of certainty in the face recognition task. The $\mathrm{z}$ scores of the responses to the wrongly recognized distracting faces (false alarms; abscissae) were plotted as a function of the $\mathrm{z}$ scores in response to the correctly recognized memorized faces (hits; ordinates).

Based on the ROC curves, the sensitivity parameter $d_{a}$ (sensitivity parameter of the group) of SDT was calculated for each experimental group. It corresponded to the distance between the distributions of the "noise" and "noise + signal" measured by the root-mean-square standard deviations of these two distributions. In this case, we obtained $d_{a}$ according to the equation $d_{\alpha}=\sqrt{2}$ / $\left(1-\beta^{2}\right) \times \alpha$, where $\alpha$ and $\beta$ are the magnitude of the linear coefficient and slope, respectively, of the zROC regression line (Fukusima, \& Landeira-Fernandez, 2012). As a more robust indicator of individual sensitivity, the three recognition categories were grouped into just one category. The same was done for the three categories of non-recognition. Thus, calculating the more traditional d' index (sensitivity parameter of the observer) was possible for each participant. We performed a mixed betweenwithin subjects analysis of variance (ANOVA), with d' and Response Time with Spatial Frequency (unfiltered, LSF filtered, and HSF filtered) as the within-subject factors and Brain Hemisphere (BH; left and right) and Sex (men and women) as the as between-subjects factors. Post hoc comparisons were performed to determine the significance of pairwise contrasts by applying Bonferroni correction. An alpha level of .05 was used. These analyses were performed using Systat 13 (Cranes).

\section{Results}

\section{Parameters $d_{\alpha}$ and $d$ '}

The same pattern of $d_{\alpha}$ of each filtered condition in both hemispheres was achieved, with better recognition of unfiltered faces (RH: .94; LH: 1.37), followed by LSF filtered faces (RH: .83; LH: .87) and HSF filtered faces (RH: .47; LH: .80), respectively. The LH/RVF was better in all filtered conditions

When $d_{\alpha}$ was extracted based on sex, men and women had different results. Men recognized unfiltered faces better than LSF and HSF filtered faces in the RH/ LVF (unfiltered: .95; LSF filtered: .76; HSF filtered: .40) and LH/RVF (unfiltered: 1.14; LSF filtered: .94; HSF filtered: .58). The RH/LVF results obtained for women followed the same pattern (unfiltered: .93; LSF filtered: .90; HSF filtered: .56). However, in the LH/RVF, the HSF filtered faces were better recognized than LSF filtered faces (unfiltered: 1.61; HSF filtered: 1.04; LSF filtered: .83). The $\mathrm{d}_{\alpha}$ data for each group were extracted from the ROC curves (Figure 3) and were consistent with the individuals' d' average.

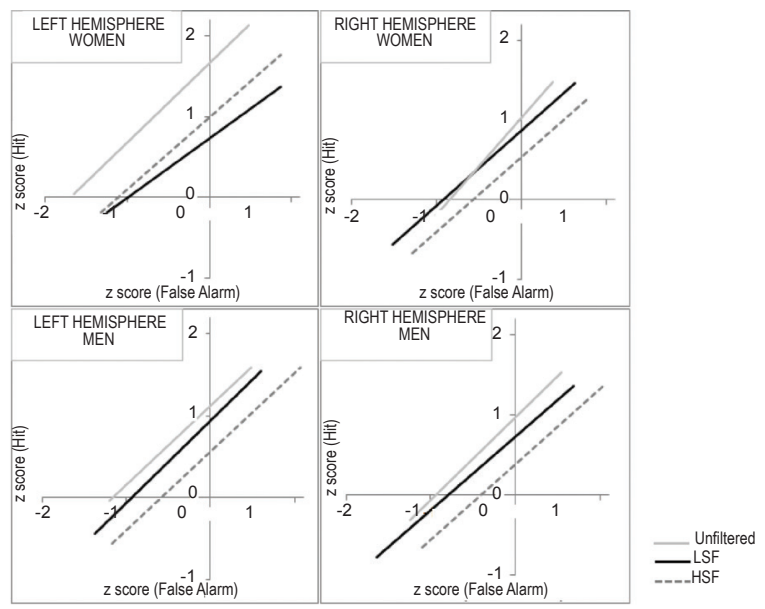

Figure 3. ROC curves on $\mathrm{z}$ coordinates for each filtering condition according to hemisphere/visual field and sex in the face recognition task. HSF, high spatial frequency; LSF, low spatial frequency; unfiltered, full spatial spectrum.

The ANOVA of d' revealed a significant $\mathrm{SF} \times \mathrm{Sex} \times$ $\mathrm{BH}$ interaction $\left(\mathrm{F}_{2,35}=3.993, \mathrm{p}=.027\right)$. But SF did not interact with Sex or BH independently. Thus, tests of the hypothesis were separated into SF, Sex, and BH analyses. The SF analysis of d' revealed a significant main effect $\left(\mathrm{F}_{2,35}=10.187, \mathrm{p}=.001\right)$. Pairwise comparisons showed significant differences between recognizing unfiltered faces and HSF filtered faces $(\mathrm{p}<.001)$.

An ANOVA was performed for each sex. A significant effect on SF recognition was found $\left(F_{2,17}\right.$ $=5.269, \mathrm{p}=.017)$. Pairwise comparisons showed that unfiltered faces were better recognized than HSF filtered faces $(p=.013)$ in males (Figure 4a). Likewise, women showed a significant effect on SF recognition $\left(\mathrm{F}_{2,17}=7.852, \mathrm{p}=.004\right)$. The unfiltered faces were better recognized than HSF filtered faces $(p=.015)$ and LSF filtered faces $(p=.035$; Figure $4 a)$. Unlike men, a significant $\mathrm{SF} \times \mathrm{BH}$ interaction was found for women $\left(\mathrm{F}_{2,17}=11.754, \mathrm{p}=.001\right)$. An ANOVA was also conducted to identify differences in face recognition by women according to $\mathrm{BH}$. A significant effect of SF on recognition was found only for the $\mathrm{LH} / \mathrm{RVF}\left(\mathrm{F}_{2,8}=\right.$ $21.051, \mathrm{p}=.001)$, indicating that unfiltered faces were better recognized than HSF filtered faces $(p=.022)$ and LSF filtered faces $(\mathrm{p}=.002$; Figure $5 \mathrm{a})$.

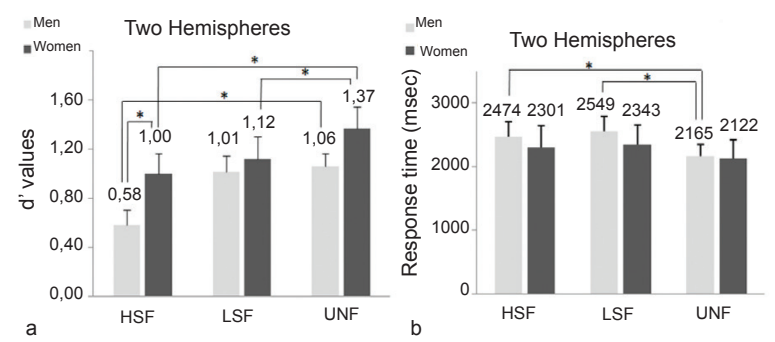

Figure 4. Comparison between sexes and hemispheres in performance in the face recognition task among filtering conditions using the d' parameter (a) and response time (b). HSF, high spatial frequency; LSF, low spatial frequency; unfiltered, full spatial spectrum. ${ }^{*} \mathrm{p}<.05$ (ANOVA). 
An ANOVA was then performed for each BH. For the RH/LVF, a significant effect of SF on recognition was found $\left(\mathrm{F}_{2,17}=6.869, \mathrm{p}=.007\right)$. Pairwise comparisons showed significant differences between unfiltered faces and HSF filtered faces $(p=.019)$ and between HSF filtered faces and LSF filtered faces $(\mathrm{p}=$ .011; Figure 5b). For the LH/RVF, a significant effect of $\mathrm{SF}$ on recognition was found $\left(\mathrm{F}_{2,17}=11.406, \mathrm{p}=\right.$ $.001)$. Unfiltered faces were better recognized than HSF filtered faces $(p=.011)$ and LSF filtered faces $(p=.017$; Figure 5b). A significant SF $\times$ Sex interaction was found $\left(\mathrm{F}_{2,17}=5.274, \mathrm{p}=.017\right)$ for the LH/RVF. An ANOVA was performed to identify the interaction between sex and filtering condition for the LH/RVF. We found that women better recognized unfiltered faces than men $\left(\mathrm{F}_{1,18}\right.$ $=6.284, \mathrm{p}=.022$; Figure 5a).

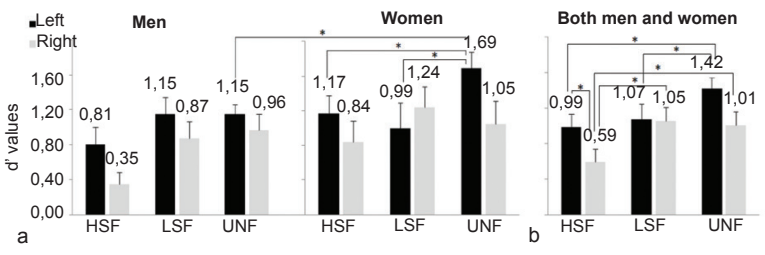

Figure 5. Comparison of performance using the d' parameter obtained in the face recognition task among filtering conditions. (a) Men and women for each hemisphere. (b) Performance for left and right hemispheres for both men and women. HSF, high spatial frequency; LSF, low spatial frequency; unfiltered, full spatial spectrum. ${ }^{*} \mathrm{p}<.05$ (ANOVA).

When contrasting individual performance based on the data obtained for HSF filtered faces as the dependent variable, we found significant effects of sex $\left(\mathrm{F}_{1,36}=\right.$ $4.580, \mathrm{p}=.039$; Figure $4 \mathrm{a})$ and $\mathrm{BH}\left(\mathrm{F}_{1,36}=3.955, \mathrm{p}=\right.$ .054 ; Figure 5b). A significant effect of $\mathrm{BH}$ was also found for unfiltered faces $\left(\mathrm{F}_{1,36}=4.601, \mathrm{p}=.039\right)$.

\section{Response time}

The ANOVA performed for RT revealed a significant $\mathrm{SF} \times \mathrm{Sex} \times \mathrm{BH}$ interaction $\left(\mathrm{F}_{2.35}=3.699, \mathrm{p}=\right.$ $.035)$, with no interaction with Sex or $\mathrm{BH}$ independently. Again, tests of the hypothesis were separated into SF, Sex, and BH analyses. The SF analysis of RT revealed a significant main effect $\left(\mathrm{F}_{2,35}=7.096, \mathrm{p}=.003\right)$, indicating that unfiltered faces were recognized faster than HSF filtered faces $(\mathrm{p}=.011)$ and LSF filtered faces $(\mathrm{p}=.001)$.

Separate ANOVAs for each sex showed that women recognized all face stimuli equally, whereas men had significant differences $\left(\mathrm{F}_{2,17}=7.396, \mathrm{p}=.005\right)$. Pairwise comparisons showed that unfiltered faces were recognized faster than LSF filtered faces $(p=.004)$ and HSF filtered faces $(p=.054$; Figure $4 b)$.

An ANOVA was performed for each BH. For the $\mathrm{RH} / \mathrm{LVF}$, a significant effect of SF on recognition was found $\left(\mathrm{F}_{2,17}=5.412, \mathrm{p}=.015\right)$. Unfiltered faces were recognized faster $(\mathrm{p}=.011)$ than LSF filtered faces (Figure 6b). Comparisons of individual performance revealed a Sex $\times \mathrm{BH}$ interaction for $\mathrm{HSF}$ filtered faces $\left(\mathrm{F}_{1,36}=4.521, \mathrm{p}=.04\right)$. This interaction was found specifically for the $\mathrm{LH} / \mathrm{RVF}$, with a significant difference between sexes $\left(\mathrm{F}_{1,18}=5.037, \mathrm{p}=.038\right)$. Women recognized HSF filtered faces faster than men (Figure 6a).

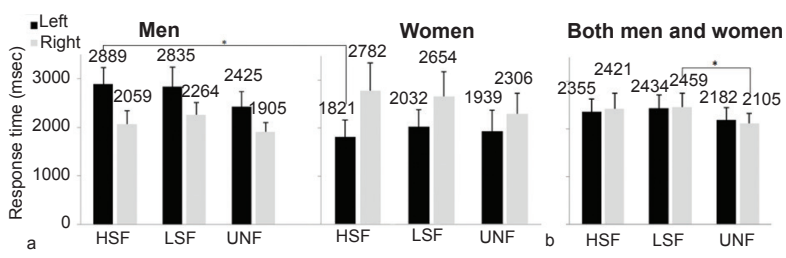

Figure 6. Response time for each filtering condition in the face recognition task. (a) Men and women for each hemisphere. (b) Performance for left and right hemispheres for both men and women. HSF, high spatial frequency; LSF, low spatial frequency; unfiltered, full spatial spectrum. ${ }^{*} \mathrm{p}<$ .05 (ANOVA).

\section{Discussion}

The present study investigated sex differences in hemispheric asymmetry in a face recognition task under the influence of spatial filtering. The results indicated that women and men differed with regard to both sensitivity and RT as a function of SF and hemispheric asymmetry.

Early studies of hemispheric lateralization with the processing of emotional stimuli, including faces (Proverbio, Brignone, Matarazzo, Del Zotto, \& Zani, 2006), facial recognition (Godard, \& Fiori, 2010), face discrimination (Hausmann, \& Gunturkun, 1999), the recognition of natural scenes with spatial filtering (Peyrin et al., 2006a), an attentional probe task (Davidson, Cave, \& Sellner, 2000), and a spatial task (Gur et al., 2000), demonstrated that men are more lateralized than women. In the present study, we did not find hemispheric specialization in men. They had the same pattern of recognition for both hemispheres when considering SDT ( $\mathrm{d}_{\alpha}$ and $\left.\mathrm{d}^{\prime}\right)$ and RTs. The best performance occurred for unfiltered faces, followed by LSF filtered faces. The worst performance was found for HSF filtered faces. Among women, no significant effect was found for SF hemispheric specialization. Based on the descriptive statistics, we observed an inversion of patterns in the recognition of faces with spatial filtering between $\mathrm{BHs}$, with better recognition of HSF and LSF filtered faces in the LH/RVF and RH/ LVF, respectively, supporting the hypothesis of Sergent (1982b). Furthermore, women had better performance recognizing unfiltered faces and were faster recognizing HSF filtered faces with the LH/RVF than men. With regard to differences in RT, the descriptive data, independent of filtering condition, showed that women were also faster recognizing stimuli with the $\mathrm{LH} / \mathrm{RVF}$, and men were faster with the RH/LVF. These results are consistent with Roalf, Lowery, \& Turetsky (2006), who studied hierarchical stimuli and event-related potentials 
(ERPs). Their ERP data showed that women were lateralized with LH/RVF dominance, especially for local stimuli. Women also had a RT delay for global stimuli. In that study, men showed similar results between stimulus conditions (i.e., global and local) and hemispheres and had lower RTs to global stimuli. Women have more efficient analytical processing, and they respond more quickly to local stimuli than to global stimuli (Roalf et al., 2006). Moreover, men presented longer RTs when visual processing was performed by the LH/RVF than by the RH/LVF (Godard, \& Fiori, 2010).

When the analysis was performed independently of sex, Sergent's hypothesis (1982b) could be partially corroborated. The main difference between BHs was found in HSF filtered faces. Stimuli with a HSF presented to the $\mathrm{LH} / \mathrm{RVF}$ were easier to recognize than stimuli presented to the RH/LVF, regardless of sex. Unfiltered and LSF filtered faces were better recognized than HSF filtered faces when presented in the RH/LVF. Our results are consistent with many studies that have supported the SF hypothesis of hemispheric specialization (Coubard et al., 2011; Evert, \& Kmen, 2003; Keenan et al., 1989; Kitterle et al., 1993; Peyrin et al., 2004; Peyrin et al., 2003; Proverbio et al., 1997; Yamaguchi, Yamagata, \& Kobayashi, 2000).

With regard to hemisphere dominance in face recognition, the literature reports an advantage of the RH/LVF (Gazzaniga, 2000; Levy, Trevarthen, \& Sperry, 1972; Ramon, \& Rossion, 2012; Springer, \& Deutch, 1993; Whitman, \& Keegan, 1991; Yovel, Tambini, \& Brandman, 2008). We did not find an advantage of the RH/LVF for face recognition with regard to either sensitivity or speed in any of the filtering conditions. One of the reasons why the RH/LVF was not better than the LH/RVF for facial recognition might be that the stimulus exposure time was $300 \mathrm{~ms}$. The advantage in analytical processing of complex stimuli performed by the LH/RVF would be impaired by a short exposure time (Sergent, 1982a). Additionally, holistic processing is more pronounced in the RH/LVF in the early stages of perception (Ramon, \& Rossion, 2012). As suggested by previous studies, the stimulus exposure time could be a key factor to establish cerebral asymmetry in visual tasks (Peyrin, Mermillod, Chokron, \& Marendaz, 2006b; Sergent, \& Hellige, 1986).

The exposure time was based on previous studies of the activity of neural pathways responsible for the recognition of facial identity in both spatial and temporal dimensions. Another reason why a $300 \mathrm{~ms}$ exposure time was used in the present study was the absence of external face features. Several studies found that external face features are primordial in processing the identity of unfamiliar faces. Recognizing faces without these elements increases the difficulty, and judgments become slower (Bobes, Martin, Olivares, \& Valdes-Sosa, 2000; Caldara, Jermann, Arango, \& Van der Linden, 2004).

The present results may have been influenced by the methodological procedures and task demands.
A longer exposure time increases interhemispheric communication and reduces cerebral asymmetry as well as the presentation of dichoptic images (Lux et al., 2004; Peyrin et al., 2006b). Likewise, a short time restriction favors analytical processing (Hegdé, 2008; Goffaux, Peters, Haubrechts, Schiltz, Jansma, \& Goebel, 2011). Despite the differences in RTs, men and women had higher rates of recognition with the LH/RVF.

Generally, when sex and BH were not considered in the analyses, unfiltered faces were recognized better and faster than filtered images. This is consistent with the literature, which suggests that faces are more sensitive to SF information (Goffaux et al., 2011). The recognition of unfiltered faces only showed statistically significant differences compared with the recognition of HSF filtered faces. The fact that unfiltered faces and LSF filtered faces showed no statistically significant difference could be related to three factors. First, the stimulus presentation was performed on peripheral vision, which is more sensitive to LSFs (Livingstone, \& Hubel, 1988). Second, the literature assumes that LSF information supports global processing, which is the automatic configuration (i.e., default configuration) of visual attention. In other words, it requires less activation than local processing (Lux et al., 2004). Third, the extraction of LSF information is important because the facial pattern is initially processed holistically (Goffaux, \& Rossion, 2006).

One of the main advantages of the present study was the equal distribution of participants of both sexes. A large amount of spatial frequency and hemispheric asymmetry research has not included samples with the same number of men and women (Evert, \& Kmen, 2003; Goffaux, Hault, Michel, Vuong, \& Rossion, 2005) and usually included samples of only one sex, usually male (Whitman, \& Keegan, 1991; Peyrin et al., 2003) or did not report the number of participants of each sex (Hills, \& Lewis, 2009; Reinvang, Magnussen, \& Greenlee, 2002). For this reason, information about sex differences in hemispheric asymmetry in visual tasks is limited. Another advantage of the present study was the unique technique of image presentation (Tripathy et al., 1995). This adaptation is very affordable, which may thus promote research in laboratories that do not have an eye tracker. Even if saccadic eye movements occur, this technique assures that no visual sweep occurs in the hemisphere's ipsilateral hemifield. For this reason, using an exposure time of $300 \mathrm{~ms}$ was possible, which is not usual in psychophysical experiments that use divided visual fields. A further advantage of this work is the SDTconfidence rating method (Macmillan, \& Creelman, 2005) that was used to analyze the participants' performance. It allows the calculation of a ROC curve and sensitivity that considers the decision criterion for each participant in a single experimental session.

In summary, the samples of men and women, when analyzed independently, did not corroborate the SF hemispheric asymmetry hypothesis. Men were more 
symmetrical than women and recognized LSF filtered faces better than HSF filtered faces. However, descriptive data suggest shorter RTs when the stimuli are presented in the RH/LVF. Women more quickly recognized the stimuli presented in the LH/RVF and HSF filtered faces. Nonetheless, women had better performance in the LH/ RVF in recognizing unfiltered faces. When the sex of the participants was not considered, Sergent's (1982b) hypothesis was partially supported. The HSF filtered faces were better recognized by the LH/RVF, and LSF filtered faces were better recognized than HSF filtered faces in the RH/LVF. In contrast to the literature, the RH/LVF was not better in the recognition task than the LH/RVF. This may be related to the use of a longer exposure time compared with other studies in the literature. We conclude that men and women have different sensitivity and RTs when recognizing faces in cerebral asymmetry research.

\section{Acknowledgements}

The authors are grateful to Prof. José Antonio Aznar Casanova for providing the MATLAB codes used to filter the images and Ana Irene Fonseca Mendes who suggested the use of an adaptation in the divided visual field method. We also thank the participants for their commitment to the study, Conselho Nacional de Desenvolvimento Científico e Tecnológico (CNPq) and Fundação de Amparo à Pesquisa do Estado de São Paulo (FAPESP) for financial aid.

\section{References}

Barbeau, E. J., Taylor, M. J., Regis, J., Marquis, P., Chauvel, P., \& Liégeois-Chauvel, C. (2008). Spatio temporal dynamics of face recognition. Cerebral Cortex, 18(5), 997-1009.

Bobes, M. A., Martin, M., Olivares, E., \& Valdes-Sosa, M. (2000). Different scalp topography of brain potentials related to expression and identity matching of faces. Cognitive Brain Research, 9(3), 249-260.

Boeschoten, M. A., Kemner, C., Kenemans, J. L., \& Engeland, H. V. (2005). The relationship between local and global processing and the processing of high and low spatial frequencies studied by event-related potentials and source modeling. Brain Research, 24(2), 228-236.

Caldara, R., Jermann, F., Arango, G. L., \& Van der Linden, M. (2004). Is the N400 category-specific? A face and language processing study. Neuroreport, 15(17), 2589-2593.

Campbell, F. W., \& Robson, J. G. (1968). Application of Fourier analysis to the visibility of gratings. Journal of Physiology, 197(3), 551-566.

Collin, C. A., Liu, C. H., Troje, N. F., McMullen, P. A., \& Chaudhuri, A. (2004). Face recognition is affected by similarity in spatial frequency range to a greater degree than within-category object recognition. Journal of Experimental Psychology: Human Perception and Performance, 30(5), 975-987.

Coubard, O. A., Perez, C., Kazandjian, S., Gaudry, I., Marendaz, C., Guyader, N., Peyrin, C., \& Chokron, S. (2011). Visual demand and visual field presentation influence natural scene processing. Graefes Archive for Clinical and Experimental Ophthalmology, 249(2), 223-232.

Davidson, H., Cave, K. R., \& Sellner, D. (2000). Differences in visual attention and task interference between males and females reflect differences in brain laterality. Neuropsychologia, 38(4), 508-519.

de Heering, A., Turati, C., Rossion, B., Bulf, H., Goffaux, V., \& Simion, F. (2008). Newborns' face recognition is based on spatial frequencies below 0.5 cycles per degree. Cognition, 106(1), 444-454.

Evert, D. L., \& Kmen, M. (2003). Hemispheric asymmetries for global and local processing as a function of stimulus exposure duration. Brain and Cognition, 51(1), 115-142.
Fukusima, S. S., \& Landeira-Fernandez, J. (2012). Informações complementares sobre a teoria de detecção do sinal aplicada à psicofísica. In J. Landeira-Fernandez, \& S.S. Fukusima (Eds.), Métodos em neurociência (pp. 24-33). Barueri: Manole.

Gazzaniga, M. S. (2000). Cerebral specialization and interhemispheric communication: does the corpus callosum enable the human condition? Brain, 123(7), 1293-1326.

Gao, Z., \& Bentin, S. (2011). Coarse-to-fine encoding of spatial frequency information into visual short-term memory for faces but impartial decay. Journal of Experimental Psychology: Human Perception and Performance, 37(4), 1051-1064.

Godard, O., \& Fiori, N. (2010). Sex differences in face processing: are women less lateralized and faster than men? Brain and Cognition, 73(3), 167-175.

Goffaux, V., Hault, B., Michel, C., Vuong, Q. C., \& Rossion, B. (2005). The respective role of low and high spatial frequencies in supporting configural and featural processing of faces. Perception, 34(1), 77-86.

Goffaux, V., Peters, J., Haubrechts, J., Schiltz, C., Jansma, B., \& Goebel, R. (2011). From coarse to fine? Spatial and temporal dynamics of cortical face processing. Cerebral Cortex, 21(2), 467-476.

Goffaux, V., \& Rossion, B. (2006). Faces are "spatial": holistic face perception is supported by low spatial frequencies. Journal of Experimental Psychology: Human Perception and Performance, 32(4), 1023-1039.

Gur, R. C., Alsop, D., Glahn, D., Petty, R., Swanson, C. L., Maldjian, J. A., Turetsky, B. I., Detre, J. A., Gee, J., \& Gur, R. E. (2000). An fMRI study of sex differences in regional activation to a verbal and a spatial task. Brain and Language, 74(2), 157-170.

Han, S., Weaver, J. A., Murray, S. O., Kang, X., Yund, E. W., \& Woods, D. L. (2002). Hemispheric asymmetry in global/local processing: effects of stimulus position and spatial frequency. NeuroImage, 17(3), 1290-1299.

Hausmann, M., \& Gunturkun, O. (1999). Sex differences in functional cerebral asymmetries in a repeated measures design. Brain and Cognition, 41(3), 263-275.

Hegdé, J. (2008). Time course of visual perception: coarse-to-fine processing and beyond. Progress in Neurobiology, 84(4), 405-439.

Hills, P. J., \& Lewis, M. B. (2009). A spatial frequency account of the detriment that local processing of Navon letters has on face recognition. Journal of Experimental Psychology: Human Perception and Performance, 35(5), 1427-1442.

Keenan, P. A., Whitman, R. D., \& Pepe, J. (1989). Hemispheric asymmetry in the processing of high and low spatial frequencies: a facial recognition task. Brain and Cognition, 11(2), 229-237.

Kitterle, F. L., Christman, S., \& Conesa, J. (1993). Hemispheric differences in the interference among components of compound gratings. Perception and Psychophysics, 54(6), 785-793.

Levy, J., Trevarthen, C., \& Sperry, R. W. (1972). Reception of bilateral chimeric figures following hemispheric deconnexion. Brain, 95(1), 61-78.

Livingstone, M., \& Hubel, D. (1988). Segregation of form, color, movement, and depth: anatomy, physiology, and perception. Science, 240(4853), 740-749.

Lux, S., Marshall, J. C., Ritzl, A., Weiss, P. H., Pietrzyk, U., Shah, N. J., Zilles, K., \& Fink, G. R. (2004). A functional magnetic resonance imaging study of local/global processing with stimulus presentation in the peripheral visual hemifields. Neuroscience, 124(1), 113-120

Macmillan, N., \& Creelman, C. (2005). Detection theory: a user's guide, 2nd edition. Mahwah, N.J.: Lawrence Erlbaum Associates.

Maurer, D., Le Grand, R., \& Mondloch, C. J. (2002). The many faces of configural processing. Trends in Cognitive Sciences, 6(6), 255-260.

Mendes, A. I. F., Arrais, K. C., \& Fukusima, S. S. (2009). Faces prototípicas provenientes de amostras populacionais de uma região brasileira. Psicologia: Reflexão e Crítica, 22(2), 261-268.

Münte, T. F., Brack, M., Grootheer, O., Wieringa, B. M., Matzke, M., \& Johannes, S. (1998). Brain potentials reveal the timing of face identity and expression judgments. Neuroscience Research, 30(1), 25-34.

Münte, T. F., Urbach, T. P., Düzel, E., \& Kutas, M. (2000). Eventrelated brain potentials in the study of human cognition and neuropsychology. In f. Boller, J. Grafman, \& G. Rizzolatti (Eds.), Handbook of neuropsychology, 2nd edition, Vol. 1 (pp. 1-97). Amsterdam: Elsevier. 
Oldfield, R. C. (1971). The assessment and analysis of handedness: the Edinburgh Inventory. Neuropsychologia, 9, 97-113.

Paller, K. A., Gonsalves, B., Grabowecky, M., Bozic, V. S., \& Yamada, S. (2000). Electrophysiological correlates of recollecting faces of known and unknown individuals. NeuroImage, 11(2), 98110.

Paller, K. A., Ranganath, C., Gonsalves, B., LaBar, K. S., Parrish, T.B., Gitelman, D. R., Mesulam, M. M., \& Reber, P. J. (2003). Neural correlates of person recognition. Learning and Memory, 10(4), 253-260

Peyrin, C., Baciu, M., Segebarth, C., \& Marendaz, C. (2004). Cerebral regions and hemispheric specialization for processing spatial frequencies during natural scene recognition: an event-related fMRI study. Neuroimage, 23(2), 698-707.

Peyrin, C., Chauvin, A., Chokron, S., \& Marendaz, C. (2003). Hemispheric specialization for spatial frequency processing in the analysis of natural scenes. Brain and Cognition, 53(2), 278-282.

Peyrin, C., Chokron, S., Guyader, N., Gout, O., Moret, J., \& Marendaz, C. (2006a). Neural correlates of spatial frequency processing: a neuropsychological approach. Brain Research, 16(1073-1074), 1-10.

Peyrin, C., Mermillod, M., Chokron, S., \& Marendaz, C. (2006b). Effect of temporal constraints on hemispheric asymmetries during spatial frequency processing. Brain and Cognition, 62(3), 214220.

Proverbio, A. M., Brignone, V., Matarazzo, S., Del Zotto, M., \& Zani, A. (2006). Gender differences in hemispheric asymmetry for face processing. BMC Neuroscience, 7, 44.

Proverbio, A. M., Zani, A., \& Avella, C. (1997). Hemispheric asymmetries for spatial frequency discrimination in a selective attention task. Brain and Cognition, 34(2), 311-320.

Ramon, M., \& Rossion, B. (2012). Hemisphere-dependent holistic processing of familiar faces. Brain and Cognition, 78(1), 7-13.

Reinvang, I., Magnussen, S., \& Greenlee, M. W. (2002). Hemispheric asymmetry in visual discrimination and memory: ERP evidence for the spatial frequency hypothesis. Experimental Brain Research, 144(4), 483-495.
Roalf, D., Lowery, N., \& Turetsky, B. I. (2006). Behavioral and physiological findings of gender differences in global-local visual processing. Brain and Cognition, 60(1), 32-42.

Sergent, J. (1982a). About face: left-hemisphere involvement in processing physiognomies. Journal of Experimental Psychology: Human Perception and Performance, 8(1), 1-14.

Sergent, J. (1982b). The cerebral balance of power: confrontation or cooperation? Journal of Experimental Psychology: Human Perception and Performance, 8(2), 253-272.

Sergent, J., \& Hellige, J. B. (1986). Role of input factors in visual-field asymmetries. Brain and Cognition, 5(2), 174-199.

Springer, S. P., \& Deutsch, G. (1993). Left brain, right brain, 4th edition. New York: W.H. Freeman.

Schwarzer, G., \& Zauner, N. (2003). Face processing in 8-month-old infants: evidence for configural and analytical processing. Vision Research, 43, 2783-2793.

Tripathy, S., Levi, D., Ogmen, H., \& Harden, C. (1995). Perceived length across the physiological blind spot. Visual Neuroscience, 12(2), 385-402.

Voyer, D. (1996). On the magnitude of laterality effects and sex differences in functional lateralities. Laterality, 1(1), 51-83.

Whitman, R. D., \& Keegan, J.F. (1991). Lateralization of facial processing: a spatial frequency model. International Journal of Neuroscience, 60(3-4), 177-185.

Yamaguchi, S., Yamagata, S., \& Kobayashi, S. (2000). Cerebral asymmetry of the "top-down" allocation of attention to global and local features. Journal of Neuroscience, 20(9), RC72.

Yovel, G., Levy, J., Grabowecky, M., \& Paller, K. A. (2003). Neural correlates of the left-visual-field superiority in face perception appear at multiple stages of face processing. Journal of Cognitive Neuroscience, 15(3), 462-474.

Yovel, G., Tambini, A., \& Brandman, T. (2008). The asymmetry of the fusiform face area is a stable individual characteristic that underlies the left-visual-field superiority for faces. Neuropsychologia, 46(13), 3061-3068.

Yue, X., Tjan, B. S., \& Biederman, I. (2006). What makes faces special? Vision Research, 46(22), 3802-3811. 